Cite this: I. Mater. Chem. A, 2013, 1 8636

Received 28th February 2013

Accepted 9th May 2013

DOI: $10.1039 / c 3 t a 10858 a$

www.rsc.org/MaterialsA

\section{A novel route to the engineering of zirconium immobilized nano-scale carbon for arsenate removal from water $\dagger$}

\begin{abstract}
Narahari Mahanta and J. Paul Chen*
Carbon nanoparticles often contain several tunable functional groups on the surface that bring about many interesting and unique properties. In this study, a novel class of hydrophilic carbons on a nanometer scale was prepared from waste biomass with hydroxyl groups on the surface. Electron microscopic studies showed that the prepared carbon particles have sizes of 50-70 nm. Raman spectroscopy revealed that these particles were amorphous in nature with no aromatization. Zirconium(Iv) was then chemically immobilized to the hydroxyl group of the carbon under basic conditions. It was found that zirconium $(\mathrm{Zr})$ ions were successfully bound onto the nano-scale carbons (NSC). The toxicity of the Zr-immobilized NS carbon (ZNC) was investigated using breast cancer stem cells (MCF7); no cytotoxic effects on the cells were found after 5 days of incubation. The nano-scaled adsorbent was used for the adsorption of arsenic. It was found that 70 to $75 \%$ of its final adsorption was achieved within the first $10 \mathrm{~min}$, much faster than many other adsorbents. The high oxophilicity of $\mathrm{Zr}(\mathrm{IV})$ ions results in the fast adsorption of arsenate anions. The Langmuir equation well described the adsorption isotherm; the maximum adsorption capacity was around $110 \mathrm{mg} \mathrm{g}^{-1}$ at the optimal $\mathrm{pH}$. The commonly existing anions such as fluoride, phosphate and nitrate as well as humic acid had no significant effects on the uptake. However, silicate ions had a large influence on the adsorption. Fourier transform infrared spectroscopy and X-ray photoelectron spectroscopic analysis revealed that the negatively charged arsenate forms chemical linkages with the ZNCs (via the electropositive metal $\left(\mathrm{Zr}^{4+}\right.$ ) precursor). From this study it was concluded that adsorption by ZNC would be a better solution for arsenic contaminated surface and groundwater.
\end{abstract}

\section{Introduction}

In the last few decades, tremendous progress has been made in reducing the levels of environmental contamination. Out of the existing techniques, adsorption is an economic and effective method for waste treatment, because the adsorbent can be regenerated by a suitable desorption process and its cost is relatively low. Recently, various mesoporous and nano-adsorbents are used for water treatment. ${ }^{1-5}$

There have been increasing demands for the application of novel carbonaceous materials in water treatment due to their

Department of Civil and Environmental Engineering, National University of Singapore, 10 Kent Ridge, Singapore 117576.E-mail: paulchen@nus.edu.sg; jchen.enve97@gtalumni.org $\dagger$ Electronic supplementary information (ESI) available: EDX analysis of ZNC, before and after arsenic adsorption. TEM analysis of ZNC and cell viability assay on the designed nanoparticles. Comparison of arsenic adsorption efficiency of the ZNC with the NSC. Graphs of final pH after adsorption vs. adsorption efficiency $\left(q_{\mathrm{e}}\right)$. Effect of humic acid and coexisting anions: fluoride, silicate, phosphate and nitrate on the adsorption of arsenate onto the designed sorbent. The atomic percentage data of different elements achieved from wide scan XPS spectra. See DOI: 10.1039/c3ta10858a low cost and high efficiency. Several methods have been used for the preparation of synthetic carbons, such as carbonization, electro-spinning, laser ablation and hydrothermal carbonization. ${ }^{6}$ These processes can be used for the development of porous amorphous or semi-crystalline carbonaceous materials with tunable shape, size and surface functionality.

Carbon derived from waste biomass is considered environmentally friendly and widely available on a large scale. ${ }^{7-9}$ Several metal ions were reportedly fused on to the carbonaceous materials during high temperature treatment to achieve special chemical and physical properties for use as adsorbents in water treatment. ${ }^{10,11}$ The preparation of such carbonaceous materials in high temperature environments can cause high porosity and very high surface areas that enhance adsorption capacity. ${ }^{12,13} \mathrm{On}$ the other hand, high temperatures may eliminate the surface functional groups, which makes these particles more hydrophobic. Owing to that, the design of suitable functionality on the surface of carbon materials is still challenging.

A variety of pollutants exist in various forms in contaminated water. Arsenic contamination in water systems is a serious threat and now arises as a challenging issue worldwide due to 
the acute and chronic toxicity. ${ }^{\mathbf{1 4 , 1 5}}$ Since 2006, the World Health Organization $(\mathrm{WHO})^{\mathbf{1 6}}$ and United States Environmental Protection Agency (EPA) ${ }^{17}$ have declared a concentration of $10 \mu \mathrm{g} \mathrm{L}^{-1}$ as the maximum contaminant level (MCL) for arsenic in safe drinking water. Serious health problems associated with higher concentrations of arsenic in drinking water in countries such as China, Bangladesh, and India are well reported. ${ }^{\mathbf{1 8 - 2 2}}$

Various techniques have been proposed for the removal of arsenic from water. ${ }^{2324}$ Compared to different approaches for arsenic removal, adsorption has several advantages such as low material costs and energy consumption, a good track record, high reliability, and ease of operation. The adsorption process deals with engineered solid phase substrates acting as an adsorbent for binding of pollutants by chemical and/or physical mechanisms. Several micro and nano-scale particles such as activated alumina, ${ }^{25}$ carbon char, ${ }^{26}$ titanium dioxide and iron oxide-coated sand for arsenic removal ${ }^{27}$ have been developed for decontamination for arsenic. Additional efforts for development include the functionalization of various polymeric membranes with suitable binding groups ${ }^{\mathbf{2 8 , 2 9}}$ and the use of naturally occurring cellulosic waste materials and other plant biomass. ${ }^{30,31}$ More work would have to be done on the development of cost-effective adsorbents in spite of some success in the R\&D area. For example, it is common that the equilibrium time for the adsorption of arsenic takes longer than one day. From an engineering standpoint, such an adsorbent cannot be acceptable as the hydraulic retention time of the treatment system would be large and thus the treatment cost would be high.

The present study focuses on the development of a new class of adsorbent, which has a high content of arsenic adsorption sites. A hydrophilic carbonaceous substrate was derived from readily available low-cost waste biomass. The $\mathrm{Zr}(\mathrm{Iv})$ ions were immobilized onto the hydroxyl groups of the nano-scale carbons (NSC), which were directly used for arsenic removal. The physico-chemical properties of the designed adsorbent were investigated by various analytical techniques. The toxicity of our designed particles was tested using breast cancer stem cells MCF-7 and the results are discussed in detail. A series of adsorption experiments was conducted to obtain key operational parameters for the adsorption process.

\section{Experimental}

\section{Materials}

Raw natural old leaves were collected from the tree Swietenia macrophylla of the family Meliaceae, from an area near to the National University of Singapore (NUS), Singapore. Ammonia solution $(25 \%)$ and sodium hydroxide were purchased from Merck. Zirconium(Iv) oxychloride $\left(\mathrm{ZrOCl}_{2} \cdot 8 \mathrm{H}_{2} \mathrm{O}\right)$ was purchased from SCRC (China). Sodium arsenate dibasic heptahydrate $\left(\mathrm{Na}_{2} \mathrm{HAsO}_{4} \cdot 7 \mathrm{H}_{2} \mathrm{O}\right)$ was purchased from Sigma-Aldrich. Sulfuric acid (75-97\%) was purchased from Honeywell, Specialty Chemicals Seelze GmbH, Germany. Sodium chloride (99.8\%) was purchased from Uni-Chem ${ }^{\circledR}$ Chemical Reagents. Sodium nitrate, sodium fluoride, trisodium phosphate, sodium silicate and humic acid were purchased from Sigma-Aldrich. All other chemicals were used without further purification. Millipore water was used for all experimental procedures.

\section{Preparation of sorbent}

Old tree leaves were collected from waste material and washed thoroughly with water and then dried at room temperature. For carbonization, dried leaves were treated with conc. sulfuric acid for 2 days. The resulted nano-scale carbon was washed thoroughly with DI water and treated with dilute sodium hydroxide until neutralized. The resultant neutralized NSC was dried using a lyophilizer and stored under dry conditions. The clean carbon was immersed in a $40 \%$ aqueous solution of $\mathrm{ZrOCl}_{2} \cdot 8 \mathrm{H}_{2} \mathrm{O}$ and kept for constant homogenization up to $12 \mathrm{~h}$. The NSC was soaked with Zr-salt solution and then exposed to ammonia vapour to enable crosslinking in a closed system for $12 \mathrm{~h}$. Repeated cleaning with DI water was carried out to remove excess unreacted Zr-salt. The Zr-immobilized NS carbon (ZNC) was then freeze-dried prior to use for the arsenic removal studies.

\section{Characterization of sorbent}

The morphology of the prepared carbon was recorded using field emission scanning electron microscopy (FESEM, JEOL JSM-6701F). The samples were kept on double sided carbon tape and a thin layer of platinum was coated for viewing under the electron microscope. The designed ZNC was deposited on prepared TEM copper grids and used for a transmission electron microscopy (TEM) study using a JEOL JEM 2010 instument, operating at $200 \mathrm{kV}$. Quantitative determination of arsenic and other elements was carried out by the Perkin-Elmer Optima 7300 dual view inductively coupled plasma optical emission spectrometer (ICP-OES). After adsorption experiment, the presence of arsenic was analyzed by an energy dispersive X-ray spectrophotometer (EDX, JEOL JED 2300). The surface of the sorbent was analyzed by X-ray photoelectron spectroscopy (XPS) (Kratos XPS system-Axis His-165 Ultra, Shimadzu, Japan). The XPS results were collected in binding energy form and fitted using a non-linear least-square curve fitting program (XPSPEAK41 Software). The Fourier transform infrared spectra of the samples, before and after adsorption experiments, were measured by Varian 3100 FTIR. The spectra were collected within the wave number range from 400 to $4000 \mathrm{~cm}^{-1}$. The Brunauer-Emmett-Teller (BET) surface area was measured using a $\mathrm{N}_{2}$ physical adsorption method with a surface area analyzer (Micromeritics ASAP 2020). Prior to the BET measurement, samples were degassed in a vacuum oven at $120^{\circ} \mathrm{C}$ for $10 \mathrm{~h}$. The relative pressure range $\left(P / P_{0}\right)$ of $0.05-0.30$ was used for calculating the BET surface area.

\section{Cytotoxicity analysis}

ZNC was sterilized under UV and dispersed in DI water prior to analysis. Breast cancer stem cell lines (MCF7) were purchased from a commercial source (American Type Culture Collection, USA). The maintenance and quantification procedures were followed according to ref. 32. A known number of MCF-7 cells were seeded in 96-well plates (Corning, Costar, NY) with a cell 
density of $5 \times 10^{3}$ cells per well in $100 \mu \mathrm{L}$ media and kept overnight for the adhesion of cells on the bottom of the well. A time dependent toxicity study was performed at different incubation times ( 1 day, 3 days and 5 days) after addition of the nanoparticles.

\section{Adsorption experiments}

A stock solution of sodium arsenate $\left(1000 \mathrm{mg} \mathrm{L}^{-1}\right)$ was prepared by dissolving $\mathrm{Na}_{2} \mathrm{HAsO}_{4} \cdot 7 \mathrm{H}_{2} \mathrm{O}$ in DI water. The freshly prepared arsenate stock solution was used for batch adsorption experiments by diluting to the test concentration. In the $\mathrm{pH}$ effect experiments, a stock solution of arsenate $\left(100 \mathrm{mg} \mathrm{L^{-1 }}, 50 \mathrm{~mL}\right)$ was prepared and the $\mathrm{pH}$ was varied from 1.5 to 11 . Nitric acid and/or sodium hydroxide (both $1 \mathrm{M}$ ) were used to maintain the $\mathrm{pH}$ of the arsenate test solution. Sorbent with a dosage of $1 \mathrm{~g} \mathrm{~L}^{-1}$ was added; the designed solutions were constantly shaken for $48 \mathrm{~h}$ at room temperature. The solutions were then filtered using a $0.45 \mu \mathrm{m}$ filter and the arsenic concentration of the filtrate was analyzed by ICP-OES.

Three sets of adsorption kinetic experiments were carried out under two sets of working $\mathrm{pH}$ conditions. In the first experiment, $0.5 \mathrm{~g}$ sorbent was added into $500 \mathrm{~mL}$ of arsenate solution $(200 \mathrm{ppm})$ at an initial $\mathrm{pH}$ of 2.5. In the second experiment, $50 \mathrm{mg}$ of adsorbent was added into $500 \mathrm{~mL}$ (20 ppm) of arsenate solution at the same $\mathrm{pH}$. In another approach, the adsorption experimental conditions are same as the second set of experiments, except that the initial $\mathrm{pH}$ of the solution was fixed at 7 . At different time intervals, small volume samples were withdrawn from the shaking bottle and the final arsenic concentration of the solution was determined by using ICP-OES.

In the adsorption isotherm study, arsenate solutions $(50 \mathrm{~mL})$ with a known initial concentration (10 to $200 \mathrm{ppm}$ ) were prepared in glass bottles; $50 \mathrm{mg}$ of the sorbent was added to each vial where the initial $\mathrm{pH}$ of the arsenate solution was maintained at 2.5. All designed test samples were shaken at room temperature for $48 \mathrm{~h}$ and the remaining concentration of arsenic was quantified.

Humic acid (HA) and common anions such as $\mathrm{F}^{-}, \mathrm{SO}_{4}{ }^{2-}$, $\mathrm{PO}_{4}{ }^{3-}$, and $\mathrm{SiO}_{3}{ }^{2-}$ normally exist in natural water. Hence in our investigation, the effects of their presence on the arsenic uptake were studied in detail. Arsenate solutions $(50 \mathrm{~mL})$ with an initial concentration of $100 \mathrm{ppm}$ were prepared and different concentrations of HA and coexisting anions were added into the solution. The mixture was shaken at room temperature for $48 \mathrm{~h}$ and the concentration of arsenic remaining in the samples were analyzed by ICP-OES.

\section{Results and discussion}

\section{Preparation of nano-scale carbon}

Tree leaves basically consist of three main components, cellulose, hemicellulose and lignin, where the proportion of these constituents solely depends on the source. ${ }^{33}$ Lignin acts as a cementing material and is mainly composed of polymers of arylpropane units which bind to cellulose and hemicellulose.
Hemicelluloses are short length polysaccharide based polymers and are generally amorphous in nature. However, cellulose is composed of anhydroglucose rings linked via $\beta$-1,4-glycosidic bonds. ${ }^{34}$ The bonds present in the anhydroglucose rings can be easily broken by strong acid treatment. Furthermore, the alternate hydroxyl groups of the polysaccharides can be easily removed by treatment with sulphuric acid through a dehydration reaction, leaving behind the dangling $\mathrm{C}=\mathrm{C}$ moiety. Hence strong acid treatment would cause the following changes: breaking of the glucopyranose unit, ring opening, and dehydration. These changes may cause the formation of a small carbonaceous precursor on a nanometer level. In the acid dehydration, a few left over hydroxyl groups may cause the hydrophilic behaviour of the NSC. The possible reaction pathway for the formation of NSC is shown below.

$$
\left(\mathrm{C}_{6} \mathrm{H}_{10} \mathrm{O}_{5}\right)_{n}+\text { sulfuric acid } \rightarrow 6 n \mathrm{C}+5 n \mathrm{H}_{2} \mathrm{O}
$$

The sizes of the resultant NSCs prepared by this process are 50-70 nm as shown in Fig. 1a. The BET study shows that the NSCs have a surface area of $29 \mathrm{~m}^{2} \mathrm{~g}^{-1}$ with a total pore volume of $0.0217 \mathrm{~cm}^{3} \mathrm{~g}^{-1}$. This value is much smaller than the activated carbons prepared by conventional methods. ${ }^{35}$ As the NSC is hydrophilic in nature, there may be some interactions due to hydrogen bonds in between the hydroxyl groups which may cause their compactness. In addition, there may not be any internal pores existing in the NSC. As such, the specific surface area of the NSC is lower.

Furthermore, the prepared NSCs were characterized by Raman spectroscopy. As shown in Fig. 1b, the G band is a bond stretching vibration, which is due to the $\mathrm{sp}^{2}$ sites of the short olefinic chains or aromatic rings. The $\mathrm{D}$ band is breathing vibration of a 6 fold aromatic ring, and it occurs only when the $\mathrm{sp}^{2}$ sites are in aromatic rings. It is demonstrated that the intensity of $\mathrm{G}$ band is higher, which represents the higher amount of $\mathrm{sp}^{3}$ character and $\mathrm{sp}^{2}$ with short $\mathrm{C}=\mathrm{C}$ olefinic linkages. This indicates that the prepared NSC is amorphous in nature without any regular conjugated double bonds, and with a lack of aromatization.

\section{Preparation of Zr-immobilized nano-scale carbon}

A novel vapour crosslinking technique was used for immobilization of $\mathrm{Zr}$-ions on to the hydrophilic nano-scale carbon particles, forming the ZNC. The novel adsorbent is designed for the effective removal of toxic anions such as arsenic. In the preparation, $\mathrm{Cl}^{-}$is replaced by $-\mathrm{OH}$ in basic medium to form hydroxo- and oxo-polynuclear complexes. ${ }^{36,37}$ Furthermore, the formation of alkoxide ions donates electrons to the vacant d-orbitals of the Zr-ions that results in the formation of a coordination complex. According to the HSAB concept, $\mathrm{Zr}$ (IV) ion is categorized as a hard acid. The transition metal, $\mathrm{Zr}$ (Iv) ion imparts high oxophilicity and hence has a high tendency to form complexes with arsenate ligands.

The formation of linkages after the immobilization of zirconium on to hydroxyl groups of the carbon precursor was investigated using FTIR spectroscopy. The FTIR spectra of the 

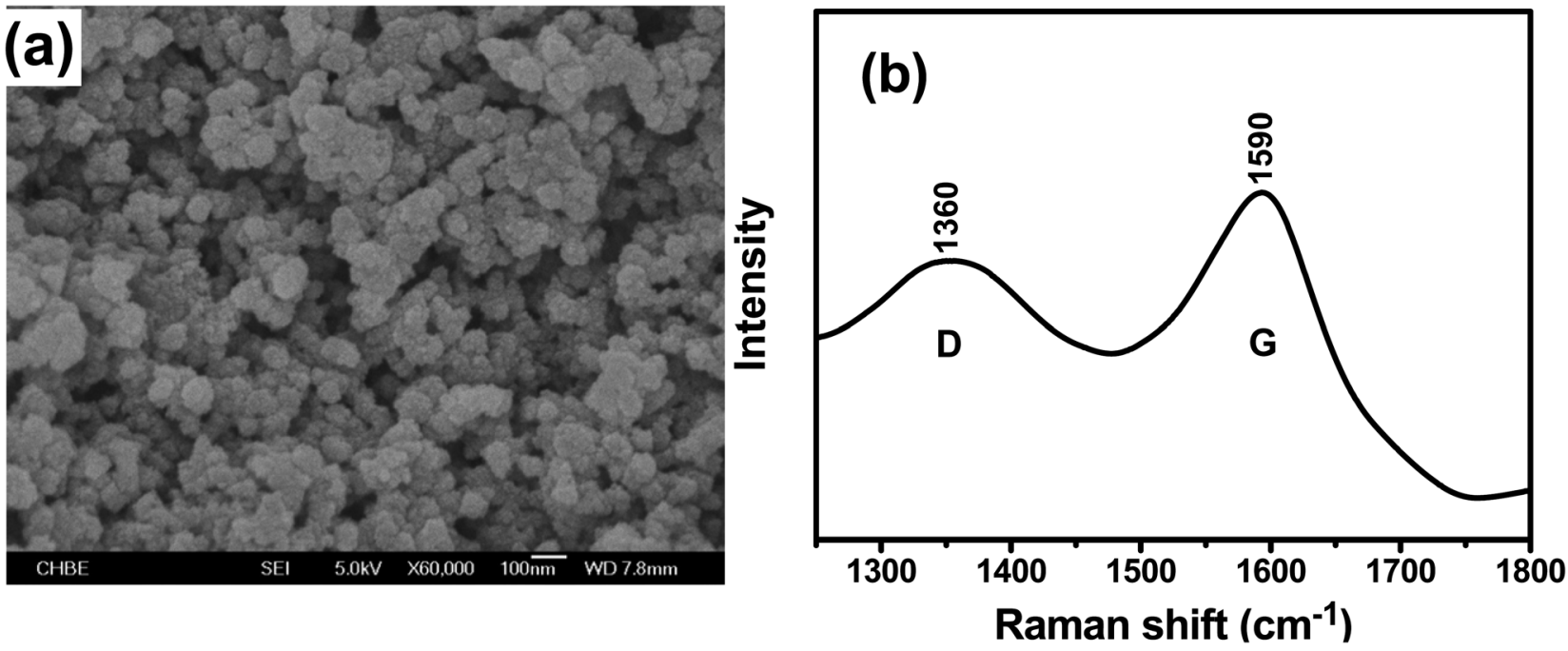

Fig. 1 Surface study of the NSC: (a) FESEM image; (b) Raman spectrum

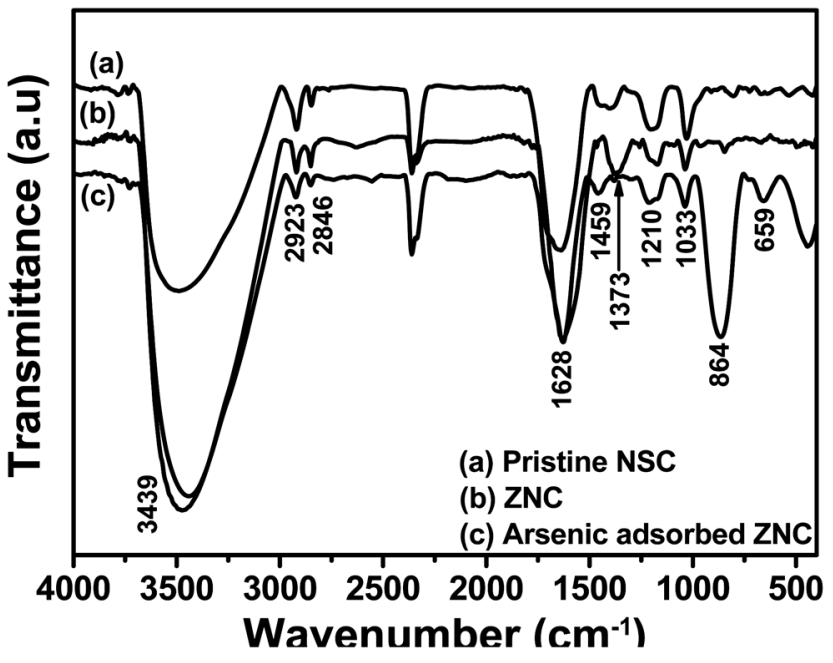

Fig. 2 FTIR spectra of the (a) pristine NSC, (b) ZNC and (c) after arsenic adsorption on to the ZNC.

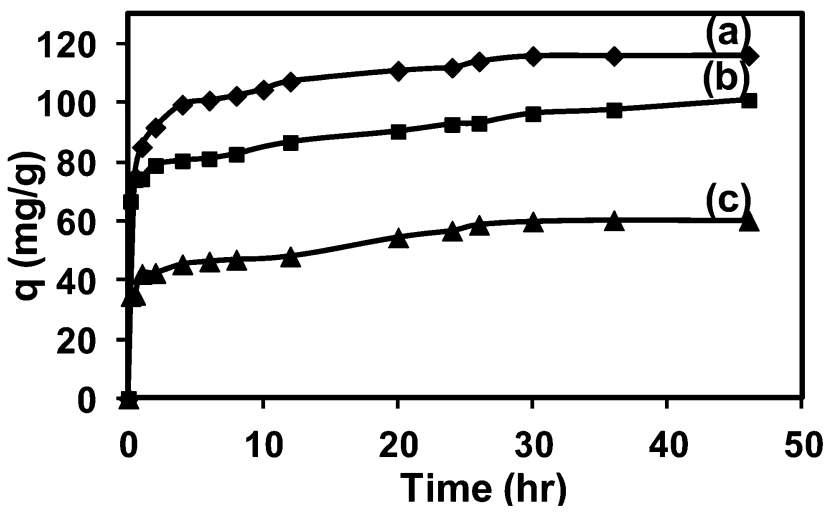

Fig. 3 Adsorption kinetics of arsenate adsorbed onto the sorbent (a) $[\mathrm{ZNC}]=1$ $\mathrm{g} \mathrm{L}^{-1},[\mathrm{As}]_{0}=200 \mathrm{ppm}, \mathrm{pH}=2.5 ;$ (b) $[\mathrm{ZNC}]=0.1 \mathrm{~g} \mathrm{~L}^{-1},[\mathrm{As}]_{0}=20 \mathrm{ppm}, \mathrm{pH}=2.5$; (c) $[\mathrm{ZNC}]=0.1 \mathrm{~g} \mathrm{~L}^{-1},[\mathrm{As}]_{0}=20 \mathrm{ppm}, \mathrm{pH}=7 ; T=22 \pm 1^{\circ} \mathrm{C}$. prepared NSCs and ZNCs are shown in Fig. 2. The wave number recording range of this experiment was from 400 to $4000 \mathrm{~cm}^{-1}$. It can be seen that there is a strong absorption peak in the range $3400-3600 \mathrm{~cm}^{-1}$ that is due to $\mathrm{O}-\mathrm{H}$ stretching vibrations; this indicates the presence of a high content of hydroxyl groups on the surface of the carbon. The absorption peaks at 2846 and $2923 \mathrm{~cm}^{-1}$ indicate the presence of $\mathrm{sp}^{3}$ and $\mathrm{sp}^{2}$ carbons, respectively. The peak at $1628 \mathrm{~cm}^{-1}$ indicates the stretching vibrations due to an unsymmetrical olefinic bond between the carbon atoms which also indicates the formation of $\mathrm{C}=\mathrm{C}$ by the dehydration reaction of the cellulose moiety. For the ZNC there is a peak at $1373 \mathrm{~cm}^{-1}$ that is due to the bending vibration of - $\mathrm{OH}$ groups on the surface of the $\mathrm{C}-\mathrm{Zr}$ adsorbent.

Furthermore, the presence of $\mathrm{Zr}$-ions on the functionalized NSC was analysed by EDX spectroscopy (ESI- $1 \uparrow$ ). From the EDX analysis, it is observed that the peak intensity of zirconium is very high; this indicates the immobilization of the zirconium moiety on to the hydroxyl groups of the NSC. Furthermore, a high amount of chlorine from $\mathrm{ZrOCl}_{2}$ is clearly absent, which reveals that the formation of a coordination complex on the ZNC. This confirms the formation of chemical bonds between the hydroxyl groups of carbon and the $\mathrm{Zr}^{4+}$ precursor.

The finding from TEM analysis of the ZNC is given in ESI- $2 . \dagger$ As the carbonaceous materials are amorphous in nature, the recorded image is not as dark as the metallic nanoparticles. In addition, some small particles can be observed, which is likely due to some hydroxide derivatives of zirconium particles on the carbon precursor.

Toxicity analysis of Zr-immobilized NSC

Nanotechnology has found wide applications in various commercial areas. Some nano-particles are reportedly toxic in nature and may cause various health hazards to human tissues. ${ }^{38}$ The toxicity caused by various nanoparticles towards living systems was documented by various groups. ${ }^{39,40}$ Our prepared nanoparticles are targeted for use in water purification. Due to 

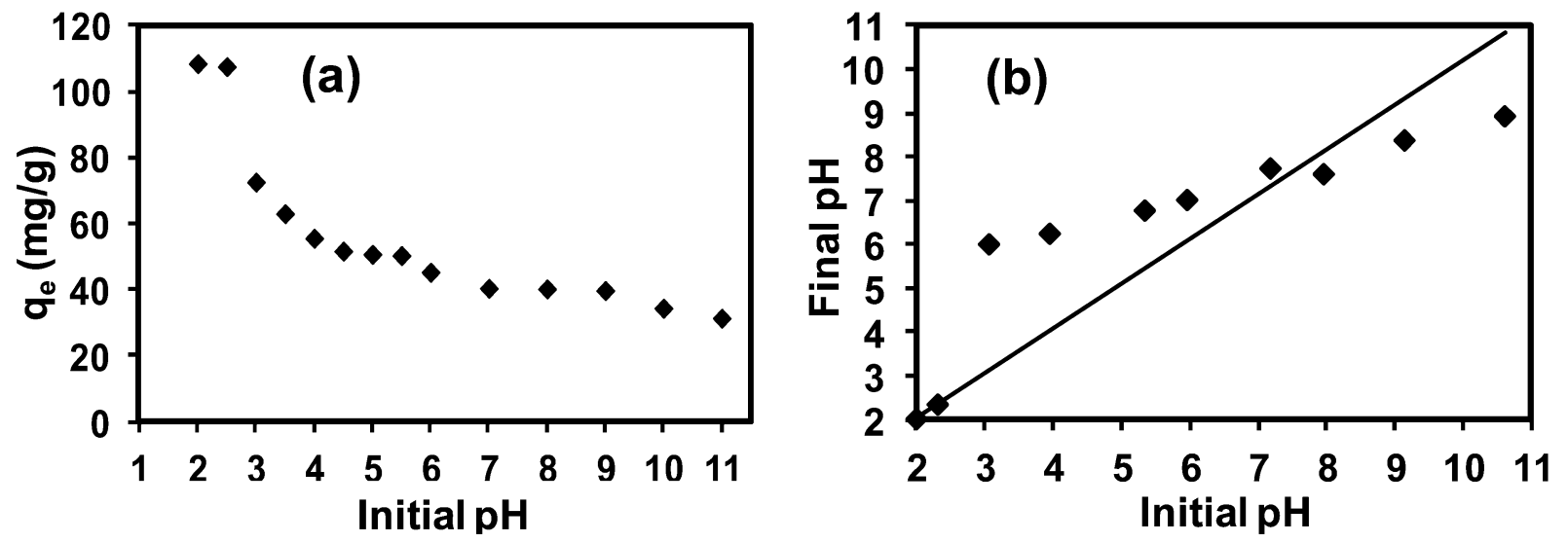

Fig. 4 Graphs of (a) the effect of initial pH on arsenate adsorption and (b) the change in solution $\mathrm{pH}$ before and after arsenate adsorption (sorbent dose $=1 \mathrm{~g} \mathrm{~L}^{-1}$, initial concentration $=100 \mathrm{mg} \mathrm{L}^{-1}, T=22 \pm 1^{\circ} \mathrm{C}$ ).

their nanometer sizes, there may be a chance that leaching of the particles during water treatment operations may occur. Hence, we studied the toxicity effect of our ZNC towards human cell lines by in vitro study. We screened the cytotoxic effects by a cell viability assay up to 5 days towards the breast cancer stem cell (MCF7). It was observed that after 5 days of co-culture, the cell morphology was normal. This finding indicates that the ZNC is not cytotoxic. Furthermore, the cell viability study at a regular interval (day 1, day 3 and day 5) (ESI-3†) shows that the material is free from any toxicity or toxic leaching.

\section{Arsenic removal study}

In natural arsenic contaminated water, arsenic exists in different oxidation states, which is dependent upon the $\mathrm{pH}$ and other environmental parameters. In the contaminated surface water and groundwater, the inorganic species generally get oxidised to arsenate by aerobic conditions.

The adsorption kinetics of arsenate onto the adsorbent is important for the design and operation of a water treatment system. Fig. 3 demonstrates the adsorption kinetics under different dosages of adsorbent and initial arsenate concentrations. An extremely fast rate of arsenate adsorption can be observed; around $70-75 \%$ of the total adsorption efficiency is achieved within the first $10 \mathrm{~min}$ for all three sets of experiments. The adsorption efficiency is higher when the initial $\mathrm{pH}$ is 2.5. At $\mathrm{pH} 7$ and an initial concentration of $20 \mathrm{ppm}$, a decrease in efficiency is observed.

The observation here illustrates that our sorbent outperforms many other sorbents for arsenic removal..$^{41}$ The arsenic adsorbed samples were characterized by EDX analysis and shown in ESI- $4 . \dagger$ From the figure it can be seen that the atomic proportions of zirconium and arsenic are around 10.3 and 5\% respectively. As during EDX analysis, carbon tape was used for fixing the samples and platinum was coated on to the heterogeneous sample surface, hence this value may not be the exact atomic percentage. Rather this study can be accounted as a qualitative measure of the presence of the arsenic moiety on the ZNC surface.

In addition, we carried out an experiment to compare the adsorption behaviour of arsenic onto the ZNC with that of the NSC. As shown in ESI-5, $\uparrow$ the adsorption efficiencies of NSC at pH 7 and $\mathrm{pH} 2.5$ are around 12 and $46 \mathrm{mg} \mathrm{g}^{-1}$, respectively. This study reveals that the NSC underperforms the ZNC in the adsorption of arsenic.

\section{Effect of $\mathbf{p H}$}

As shown in Fig. 4a, the arsenate adsorption is greatly dependent upon the solution $\mathrm{pH}$. At an acidic $\mathrm{pH}$ in the range 2 to 2.5 ,
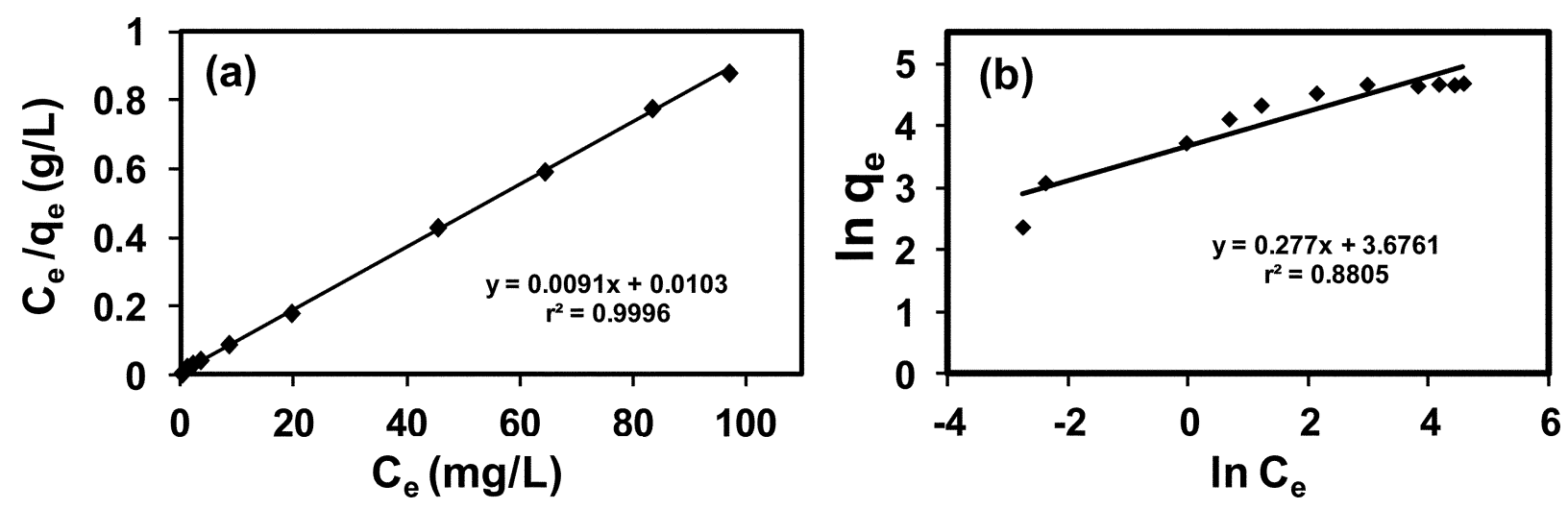

Fig. 5 Adsorption isotherm of arsenate onto the sorbent: (a) linearized Langmuir isotherm; and (b) linearized Freundlich isotherm. 
Langmuir and Freundlich isotherm constants for adsorption of arsenate

\begin{tabular}{|c|c|c|c|c|c|c|c|c|}
\hline & \multicolumn{4}{|c|}{ Langmuir parameters } & \multicolumn{4}{|c|}{ Freundlich parameters } \\
\hline & $q_{\max }\left(\mathrm{mg} \mathrm{g}^{-1}\right)$ & $b\left(\mathrm{~L} \mathrm{mg}^{-1}\right)$ & $r^{2}$ & $\chi^{2}$ & $K_{\mathrm{f}}$ & $n$ & $r^{2}$ & $\chi^{2}$ \\
\hline Linear & 109.89 & 0.883 & 0.999 & N.A & 39.5 & 3.61 & 0.880 & N. A. \\
\hline Non-linear & 110.7 & 0.703 & 0.974 & 35.07 & 51.56 & 5.405 & 0.869 & 181.73 \\
\hline
\end{tabular}

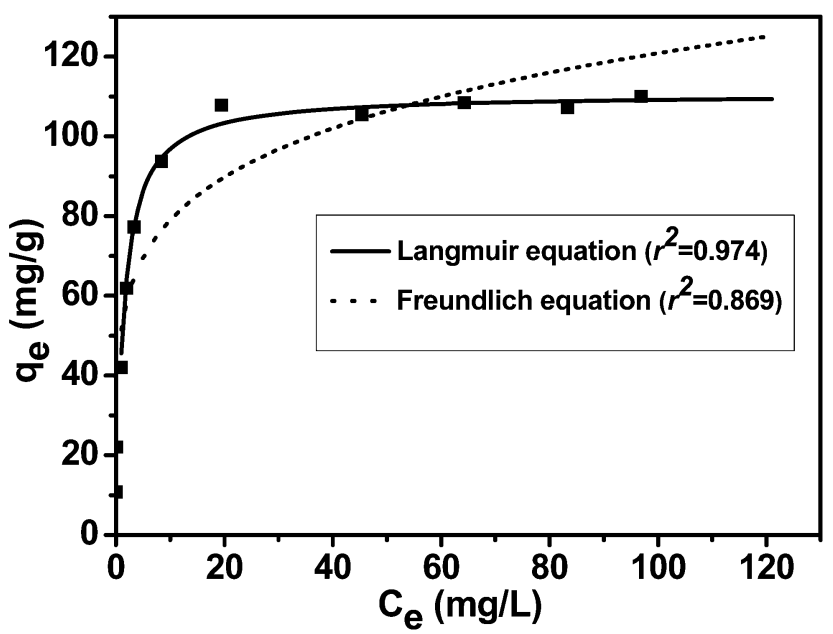

Fig. 6 Adsorption isotherms of arsenate on to the adsorbent with experimental data fitting by Langmuir and Freundlich isotherms. The curves are based on the parameters obtained by the non-linear approach.

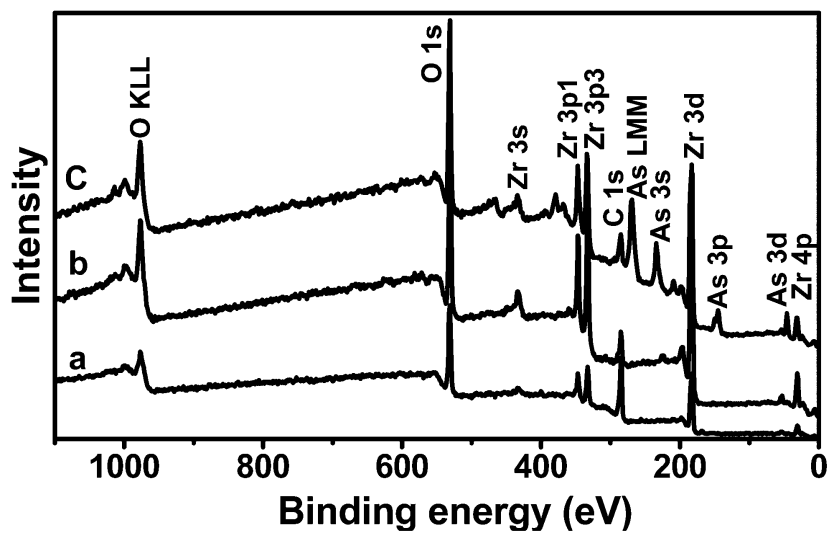

Fig. 7 Wide scan XPS spectra of (a) NSC, (b) ZNC and (c) As-bonded ZNC.

the best adsorption of around $110 \mathrm{mg}$ As per gram can be achieved. The adsorption gradually decreases with increasing pH. At $\mathrm{pH} 7 \pm 1$ that is common in surface and groundwater, the adsorption is still well maintained at $40 \mathrm{mg}$ As per gram, which outperforms many commercially available adsorbents. This result indicates that our adsorbent is suitable for the treatment of both industrial wastewater (often acidic) and surface/ground water ( $\mathrm{pH} 7 \pm 1$ ).

The higher adsorption at acidic $\mathrm{pH}$ is due to protonation on the surface of the adsorbent. Furthermore, at acidic $\mathrm{pH}$ the arsenic species is a negatively charged form such as $\mathrm{H}_{2} \mathrm{AsO}_{4}{ }^{-}$.
Hence the adsorption is favourable in acidic solutions. As the surface of sorbent becomes negatively charged at higher $\mathrm{pH}$, less sorption occurs. Fig. $4 \mathrm{~b}$ shows the $\mathrm{pH}$ before and after sorption. The sorbent seems to have a good buffering effect on the solution. The final $\mathrm{pH}$ increases when the initial $\mathrm{pH}$ is increased. Furthermore, a figure of adsorption efficiency $\left(q_{\mathrm{e}}\right) v s$. the final $\mathrm{pH}$ was plotted and shown in ESI-6. $\dagger$ It shows a decrease in the adsorption efficiency at the final $\mathrm{pH}$ in the range 2 to 6 .

\section{Adsorption isotherm}

Langmuir and Freundlich equations can be used to describe adsorption isotherms. The Langmuir model is applicable for uniform adsorption processes, where each adsorption site on the surface has identical binding sites and is described as monolayer adsorption. The equation for the Langmuir model can be expressed as follows.

$$
q_{\mathrm{e}}=\frac{q_{\max } b C_{\mathrm{e}}}{1+b C_{\mathrm{e}}}
$$

where $q_{\max }$ (in $\mathrm{mg} \mathrm{g}^{-1}$ ) is the maximum amount of the adsorbate per unit weight of adsorbent to form a complete monolayer on the surface bound at high equilibrium concentration, and $b$ is a constant related to the affinity of the binding sites $\left(\mathrm{L} \mathrm{mg}^{-1}\right)$.

The Langmuir coefficients $q_{\max }$ and $b$ can be determined from the slope and intercept of a linear plot of $C_{\mathrm{e}} / q_{\mathrm{e}}$ against $C_{\mathrm{e}}$.

The linearized equation is expressed as:

$$
\frac{C_{\mathrm{e}}}{q_{\mathrm{e}}}=\frac{1}{q_{\max }} C_{\mathrm{e}}+\frac{1}{b q_{\max }}
$$

The Freundlich adsorption isotherm mainly describes adsorption on a heterogeneous surface and is expressed as:

$$
q_{\mathrm{e}}=K_{\mathrm{f}} C_{\mathrm{e}}^{1 / n}
$$

Its linearized expression is shown as below:

$$
\ln q_{\mathrm{e}}=\ln K_{\mathrm{f}}+\frac{1}{n} \ln C_{\mathrm{e}}
$$

where $K_{\mathrm{f}}$ and $n$ are the Freundlich constants.

The manupulation of non-linear isotherm equations to linearized forms implicitly alters their error structure and may deviate the error variance and normality assumptions of the standard least squares. ${ }^{42,43}$ Hence, it is important to analyze the representative data set using the nonlinear chi-square test $\left(\chi^{2}\right)$, to figure out the appropriate isotherm for the adsorption system. $\chi^{2}$ can be determined using the following equation: 

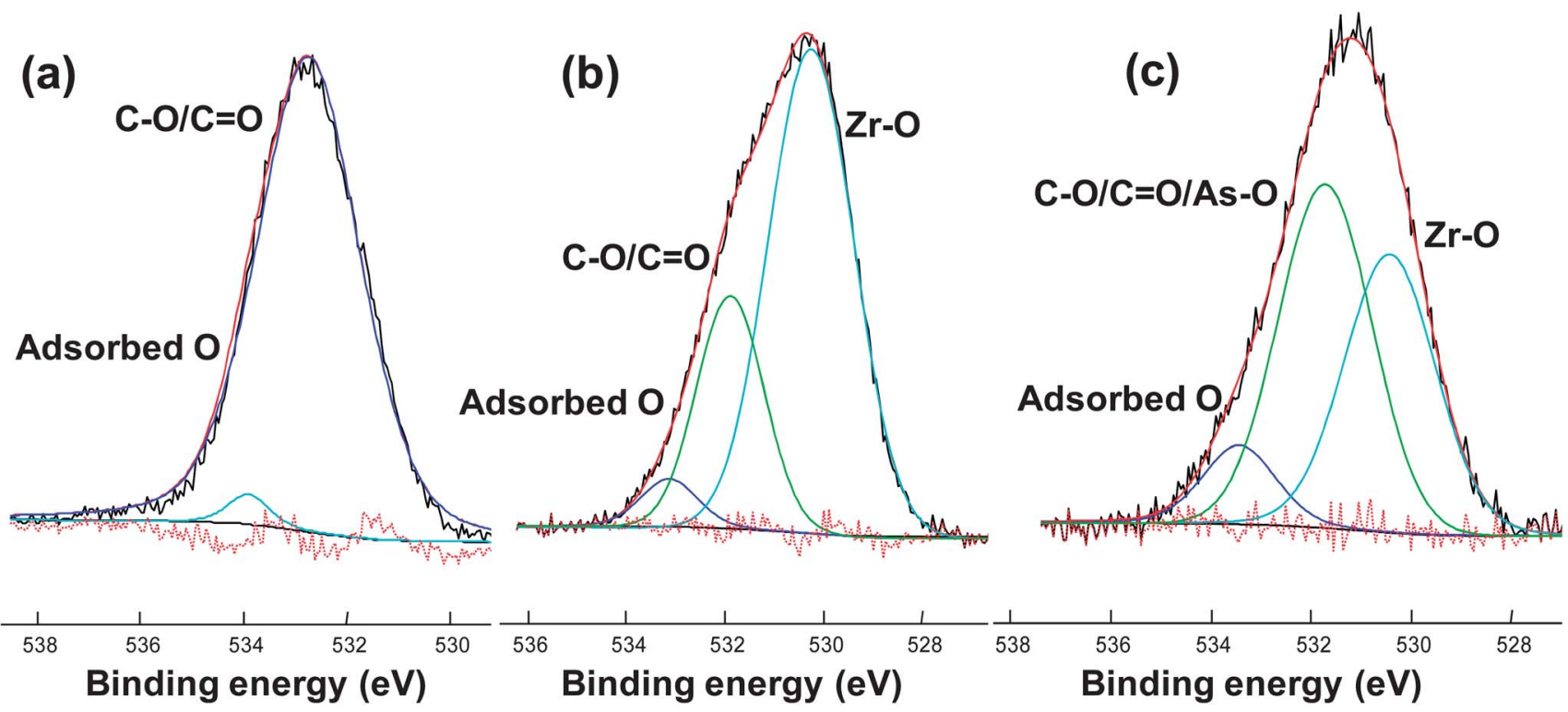

Fig. 8 High resolution XPS spectra of O 1s core-level spectrum of (a) NSC; (b) ZNC; (c) As-bonded ZNC.

$$
\chi^{2}=\sum \frac{\left(q_{\mathrm{e}}-q_{\mathrm{e}, \mathrm{m}}\right)^{2}}{q_{\mathrm{e}, \mathrm{m}}}
$$

where $q_{\mathrm{e}}$ is the experimental value of adsorption at equilibrium uptake and $q_{\mathrm{e}, \mathrm{m}}$ is the equilibrium uptake calculated using the model.

The plots of $C_{\mathrm{e}} / q_{\mathrm{e}}$ against $C_{\mathrm{e}}$ and $\ln q_{\mathrm{e}}$ versus $\ln C_{\mathrm{e}}$ are shown in Fig. 5; the parameters were calculated based on linear and non-linear approaches and correlation coefficients $\left(r^{2}\right)$ are summarized in Table 1. As shown, the experimental results were better fitted by the Langmuir isotherm when both methods for the estimation of parameters are used.

From the Langmuir model, it can be found that the maximum adsorption capacity of arsenate onto the adsorbent is as high as $110 \mathrm{mg} \mathrm{g}^{-1}$ (Fig. 6). Compared to the other existing nano-scaled sorbents for arsenic removal, ${ }^{44,45}$ our method is advantageous as the designed material is in the form of $\mathrm{Zr}(\mathrm{Iv})$, where the vacant $d$-orbitals more preferably forms bonds with arsenate anions.

\section{Effect of HA and coexisting anions}

Natural ground water contains common natural organic matter (NOM). This may affect the adsorption reaction. It may also cause blockage of the adsorption sites. ${ }^{46}$ In our study, the effect of NOM represented by humic acid (HA) on the adsorption was investigated in detail and shown in ESI-7. $\dagger$ It is shown that the presence of HA does not have any significant influence on the adsorption; around $10 \%$ reduction in the adsorption can be found when $\mathrm{HA}\left(10 \mathrm{mg} \mathrm{L}^{-1}\right)$ is present in the water.

In addition, natural water contains several anions, which may have competitive effects on the adsorption. $\mathrm{F}^{-}, \mathrm{SiO}_{3}{ }^{2-}$,
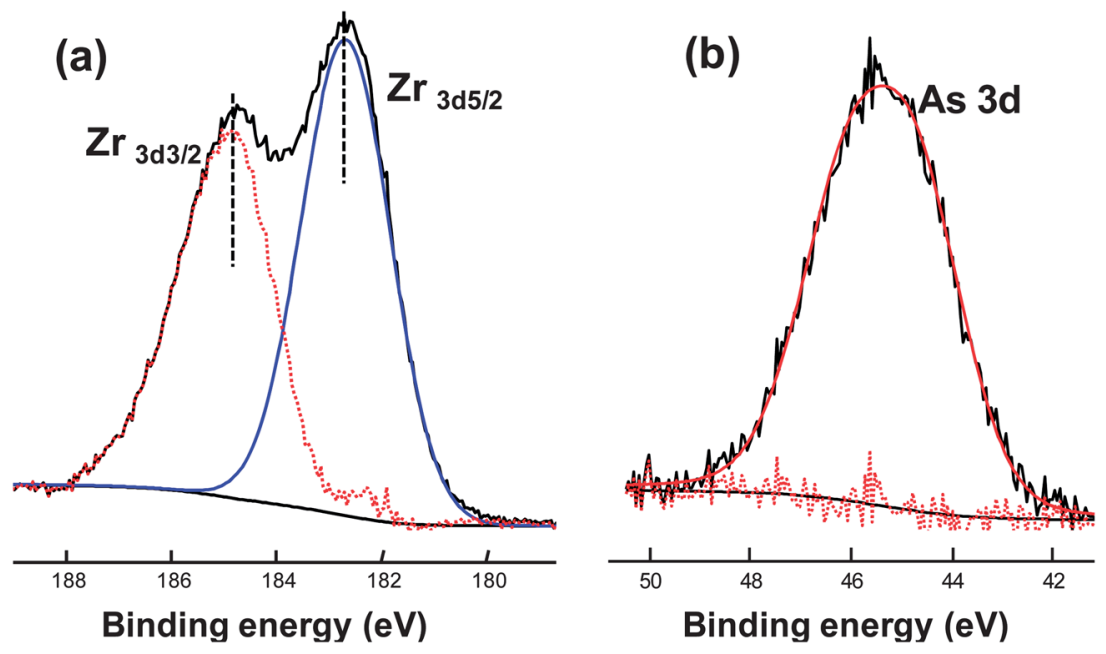

Fig. 9 High resolution XPS spectra of As-bonded ZNC: (a) Zr 3d core level spectrum; (b) As 3d core level spectrum. 
$\mathrm{PO}_{4}{ }^{2-}$ and $\mathrm{NO}_{3}{ }^{-}$were selected to represent the anions in natural water. The concentrations of the coexisting anions were within the levels present in natural environments.

As demonstrated in ESI-8, $\uparrow$ there is no significant influence on the adsorption in the presence of phosphate, nitrate and fluoride. This indicates that the arsenate acts as a stronger legend than other anions towards our designed adsorbent. However, silicate demonstrates a large influence on the adsorption behavior. On the other hand, the finding indicates that our sorbent may also have good adsorption material for the removal of silicates.

\section{Spectroscopic analysis}

The FTIR spectrum of the ZNC after arsenic adsorption is shown in Fig. 2c. There is a peak at $1373 \mathrm{~cm}^{-1}$ for $\mathrm{ZNC}$ which is due to the bending vibration of $-\mathrm{OH}$ groups on the surface of the $\mathrm{C}-\mathrm{Zr}$ adsorbent. After the arsenic adsorption, there is a peak shift to $1459 \mathrm{~cm}^{-1}$ due to the As-OH bending vibration.

A strong peak appears at $864 \mathrm{~cm}^{-1}$ after the adsorption, which is due to the combination of both symmetric and asymmetric stretching vibrations of the As-O bond. Furthermore, a small peak at $659 \mathrm{~cm}^{-1}$ can be observed, which may be due to the presence of As-OH asymmetric stretching. The above findings show solid evidence of the formation of bonds between arsenate and the designed adsorbent.

The formation of a complex is due to the loosely coordinated ligands (such as $-\mathrm{OH}_{2}$ ) on the $\mathrm{Zr}^{4+}$, which form bonds with arsenate anions. XPS was used to study the chemical properties of different adsorbents. Fig. 7a reveals the presence of only carbon (C 1s) and oxygen (O 1s) peaks on the surface of the NSC. The presence of an oxygen peak is due to the surface hydroxyl groups on the carbon, leading to the hydrophilicity. Similarly there are five characteristics peaks for zirconium on the surface of ZNC (Fig. 7b), which corresponds to the Zr 3s, Zr 3p1, Zr 3p3, Zr 3d and Zr 4p. The peak intensity for C $1 \mathrm{~s}$ in the ZNC is less than that of the NSC.

It can be observed from Fig. 7c that there are peaks which correspond to arsenic: As 3s, As 3p, As 3d and As LMM that are present on its surface. The elemental analysis of ZNC after arsenic adsorption reveals that the atomic percentages of zirconium and arsenic are around 13.5 and 6, respectively (ESI-9†). These findings confirm the adsorption of arsenic onto the sorbent. The peak intensity for $\mathrm{C} 1 \mathrm{~s}$ of As-bonded ZNC decreases compared to the wide scan spectra of NSC. This is due to the incorporation of $\mathrm{Zr}$, As and bonded oxygen. In addition, the peak intensity of $\mathrm{O} 1 \mathrm{~s}$ is increased in the case of As-bonded ZNC, due to the presence of various bonded oxygens in the adsorbent and arsenate species. The high resolution scan of the O 1s spectrum of all samples (NSC, ZNC and As-bonded ZNC) was deconvoluted into several individual peaks and is shown in Fig. 8a-c. It can be observed that there is a peak with a binding energy at $532.74 \mathrm{eV}$ because of the presence of simple $\mathrm{C}-\mathrm{O}$ or $\mathrm{C}=\mathrm{O}$ on the sorbent. In the case of $\mathrm{ZNC}$, however, it is observed that there is a clear peak with a binding energy at $530.25 \mathrm{eV}$ that can be assigned to $\mathrm{Zr}-\mathrm{O}$. The $\mathrm{C}-\mathrm{O} / \mathrm{C}=\mathrm{O}$ peak arises with a binding energy at $531.89 \mathrm{eV}$. In the case of As-bonded ZNC, the peak intensity of $\mathrm{Zr}-\mathrm{O}$ decreases drastically and the intensity of the peak at $531.72 \mathrm{eV}$ increases. After the complexation of arsenate onto the $\mathrm{ZNC}$, the proportion of arsenic increases to a greater extent and hence the combined intensity of $\mathrm{C}-\mathrm{O} / \mathrm{C}=\mathrm{O}$ / As-O increases compared to ZNC.

Furthermore, Fig. 9a shows that the ZNC has peaks with binding energies of 182.6 and $184.7 \mathrm{eV}$ that correspond to $\mathrm{Zr}$ $3 \mathrm{~d} 3 / 2$ and $\mathrm{Zr} 3 \mathrm{~d} 5 / 2$, respectively.

Fig. 9b shows the high resolution XPS spectrum of ZNC after arsenic adsorption. A clear As 3d peak appears at a binding energy of $46 \mathrm{eV}$ which confirms the presence of an arsenic species on the adsorbent, which is similar to the case of adsorption of organic arsenic previously reported. ${ }^{47}$

\section{Conclusions}

A novel route is demonstrated for the development of a new kind of adsorbent for the fast removal of arsenate from water. The hydrophilic nano-scale carbon is first prepared, which has sizes ranging from 50 to $70 \mathrm{~nm}$. Zirconium(Iv) is then immobilized onto the hydroxyl moiety of the NSC to form a highly effective sorbent $\mathrm{ZNC}$ for the removal of arsenate. The successful incorporation of zirconium onto the carbon is confirmed by EDX analysis. Cytotoxic evaluation shows that the ZNC is not toxic toward the breast cancer stem cells (MCF7) after 5 days of incubation.

The arsenate adsorption is highly dependent upon the solution $\mathrm{pH}$. The best removal can be achieved at an initial $\mathrm{pH}$ of 2 to 3. As the $\mathrm{pH}$ is increased, the removal decreases. The adsorbent apparently has a good buffering capacity for $\mathrm{pH}$. At neutral $\mathrm{pH}$, the adsorption capacity is still maintained at 40 $\mathrm{mg} \mathrm{g}^{-1}$, which is higher than many other reported adsorbent materials.

The adsorption occurs rapidly; 70 to $75 \%$ of its final removal can be achieved within $10 \mathrm{~min}$, which is much faster than many conventional adsorbents. The adsorption process follows the Langmuir adsorption behaviour. The maximum adsorption capacity is as high as $110 \mathrm{mg} \mathrm{g}^{-1}$ at optimum $\mathrm{pH}$. It is observed that humic acid, fluoride, nitrate and phosphate have no significant negative effects toward arsenate binding. However the presence of silicate greatly hinders the adsorption. FTIR spectroscopic analysis of As-bonded ZNC clearly indicates the presence of peaks at 1459 and $864 \mathrm{~cm}^{-1}$, which confirmed the chemical interaction between the negatively charged arsenate with the electropositive metal $\left(\mathrm{Zr}^{4+}\right)$ precursor. The complexation of arsenate on to the ZNC after the adsorption process was revealed by the appearance of a clear As 3d peak at a binding energy of $46 \mathrm{eV}$, and the increased intensity of the O1s peak at $531.72 \mathrm{eV}$ further confirmed the oxophilic character of the $\mathrm{Zr}$ (Iv) ions. The fast adsorption and high capacity can make the designed ZNC adsorbent a promising advanced material for the removal of arsenate from water in practical applications.

\section{Acknowledgements}

The authors would like to thank Professor Suresh Valiyaveettil and Ms Chunyen Wang from Department of Chemistry, NUS for helping the cytotoxic evaluation of the functionalized particles. 


\section{References}

1 F. S. Shariatmadar and M. Mohsen-Nia, Polym. Compos., 2012, 33, 1188-1196.

2 Y. Ma, Y. M. Zheng and J. P. Chen, J. Colloid Interface Sci., 2011, 354, 785-792.

3 A. F. C. Campos, R. Aquino, T. Cotta, F. A. Tourinho and J. Depeyrot, Bull. Mater. Sci., 2012, 34, 1357-1361.

4 T. B. Shirey, R. W. Thacker and J. B. Olson, J. Water Health, 2012, 10, 244-255.

5 W. C. Yin, J. S. Zhang, L. J. Liu, Y. Zhao, T. Li and C. Lin, J. Water Supply: Res. Technol.-AQUA, 2012, 61, 228-239.

6 A. J. Romero-Anaya, M. A. Lillo-Rodenas, C. S. M. de Lecea and A. Linares-Solano, Carbon, 2012, 50, 3158-3169.

7 Q. F. Wu and S. Zhang, Fuel, 2012, 94, 426-432.

8 J. Huang, X. D. Tan, Y. J. Yang, J. Zheng and Y. T. Wang, Adv. Sci. Lett., 2011, 4, 3512-3516.

9 M. Sindhu, K. Begum and S. Sugashini, Desalin. Water Treat., 2012, 45, 170-176.

10 N. Asasian, T. Kaghazchi and M. Soleimani, J. Ind. Eng. Chem., 2012, 18, 283-289.

11 K. B. Nagashanmugam and K. Srinivasan, Indian J. Chem. Technol., 2011, 18, 391-402.

12 A. I. Zouboulis and K. A. Matis, Crit. Rev. Environ. Sci. Technol., 1997, 27, 195-235.

13 M. A. A. Zaini, Y. Amano and M. Machida, J. Hazard. Mater., 2010, 180, 552-560.

14 A. Ray, S. Roy, S. Agarwal and S. Bhattacharya, Toxicol. Ind. Health, 2008, 24, 643-653.

15 K. Jomova, Z. Jenisova, M. Feszterova, S. Baros, J. Liska, D. Hudecova, C. J. Rhodes and M. Valko, J. Appl. Toxicol., 2011, 31, 95-107.

16 World Health Organization, Guidelines for drinking water quality, 4th edn, Switzerland, 2011, p. 178.

17 United States Environmental Protection Agency, Implementation Guidance for the Arsenic Rule, pp. 1-4.

18 G. C. Fang, Y. L. Huang and J. H. Huang, Environ. Monit. Assess., 2011, 184, 729-740.

19 J. A. Navoni, D. De Pietri, S. Garcia and E. C. V. Lepori, Revista Panamericana de Salud Pública, 2012, 31, 1-8.

20 M. Sepulveda, E. Laval, L. Cornejo and J. Acarapi, Rock Art Research, 2012, 29, 93-107.

21 R. K. Dhar, B. K. Biswas, G. Samanta, B. K. Mandal, D. Chakraborti, S. Roy, A. Jafar, A. Islam, G. Ara, S. Kabir, A. W. Khan, S. A. Ahmed and S. A. Hadi, Curr. Sci., 1997, 73, 48-59.

22 J. G. Hering, Abstracts of Papers of the American Chemical Society, 1998, 216, U796-U796.

23 C. Z. Hu, H. J. Liu, G. X. Chen and J. H. Qu, Sep. Purif. Technol., 2012, 86, 35-40.
24 A. Tubic, J. Agbaba, B. Dalmacija, I. Ivancev-Tumbas and M. Dalmacija, J. Environ. Sci. Health, Part A: Toxic/Hazard. Subst. Environ. Eng., 2010, 45, 363-369.

25 T. S. Singh and K. K. Pant, Water Qual. Res. J. Can., 2006, 41, 147-156.

26 J. Pattanayak, K. Mondal, S. Mathew and S. B. Lalvani, Carbon, 2000, 38, 589-596.

27 L. Ko, A. P. Davis, J. Y. Kim and K. W. Kim, J. Environ. Eng., 2007, 133, 891-898.

28 H. R. Akbari, A. R. Mehrabadi and A. Torabian, Iran. J. Environ. Health Sci. Eng., 2010, 7, 273-278.

29 H. Saitua, R. Gil and A. P. Padilla, Desalination, 2011, 274, 16.

30 J. A. Baig, T. G. Kazi and L. Elci, Sep. Sci. Technol., 2012, 47, 1044-1054.

31 T. S. Anirudhan, P. Senan and P. S. Suchithra, Water, Air, Soil Pollut., 2011, 220, 101-116.

32 Y. Teow and S. Valiyaveettil, Nanoscale, 2010, 2, 26072613.

33 O. F. Ali, J. T. Jian Li and J. D. Taylor, US 6896810 B2, 2005.

34 M. Sousa, A. R. Bras, H. I. M. Veiga, F. C. Ferreira, M. N. de Pinho, N. T. Correia and M. Dionisio, J. Phys. Chem. B, 2010, 114, 10939-10953.

35 X. P. Dong, J. Fu, X. X. Xiong and C. Chen, Mater. Lett., 2011, 65, 2486-2488.

36 R. B. Hernandez, A. P. Franc, O. R. Yola, A. Lopez-Delgado, J. Felcman, M. A. L. Recio and A. L. R. Merce, J. Mol. Struct., 2008, 877, 89-99.

37 H. Yokoi, Y. Mori and Y. Fujise, Bull. Chem. Soc. Jpn., 1995, 68, 2061-2065.

38 M. Ghosh, J. Manivannan, S. Sinha, A. Chakraborty, S. K. Mallick, M. Bandyopadhyay and A. Mukherjee, Mutat. Res., Genet. Toxicol. Environ. Mutagen., 2012, 749, 60-69.

39 Y. Teow, P. V. Asharani, M. P. Hande and S. Valiyaveettil, Chem. Commun., 2011, 47, 7025-7038.

40 P. V. AshaRani, G. L. K. Mun, M. P. Hande and S. Valiyaveettil, ACS Nano, 2009, 3, 279-290.

41 Z. M. Ren, G. S. Zhang and J. P. Chen, J. Colloid Interface Sci., 2011, 358, 230-237.

42 S.-J. Park and S.-Y. Jin, Carbon, 2004, 42, 2113-2115.

43 Y. S. Ho, Water Res., 2006, 40, 119-125.

44 Y. M. Zheng, L. Yu and J. P. Chen, J. Colloid Interface Sci., 2012, 367, 362-369.

45 Y. M. Zheng, L. Yu, D. Wu and J. P. Chen, Chem. Eng. J., 2012, 188, 15-22.

46 Z. M. Gu, J. Fang and B. L. Deng, Environ. Sci. Technol., 2005, 39, 3833-3843.

47 S. F. Lim, Y. M. Zheng and J. P. Chen, Langmuir, 2009, 25, 4973-4978. 